\title{
Establishing LA VIDA: A Community-Based Partnership to Prevent Intimate Violence Against Latina Women
}

\author{
Barbara J. Maciak, PhD, MPH \\ Ricardo Guzman, MSW, MPH \\ Anna Santiago, $\mathrm{PhD}$ \\ Graciela Villalobos, MSW \\ Barbara A. Israel, DrPH
}

\begin{abstract}
LA VIDA-the Southwest Detroit Partnership to Prevent Intimate Violence Against Latina Womenevolved in response to community concern about the problem of intimate partner violence (IPV) and the lack of culturally competent preventive and support services for Latino women and men in southwest Detroit. Since 1997, diverse organizations have mobilized as a community-academic partnership to ensure the availability, accessibility, and utilization of IPV services. This article describes and analyzes the evolution of LA VIDA within a community-based participatory research framework using a case study approach that draws on multiple data sources including group and individual interviews and field notes. The challenges and lessons learned in addressing a complex multifaceted problem such as IPV in an ethnic minority community are highlighted in an examination of the process of mobilizing diverse organizations, conducting community diagnosis and needs assessment activities, establishing goals and objectives within a social ecological framework, and integrating evaluation during the development phase.
\end{abstract}

The complex nature of public health problems such as intimate partner violence (IPV) — that is, physical, psychological/emotional, and/or sexual abuse against a woman by a male spouse or partner - that are rooted in a broader social, cultural, political, and economic fabric, has led to an emphasis on multiple interventions across multiple levels of the social ecology. ${ }^{1}$ The development of community coalitions for prevention and health promotion has become a popular strategy aimed at building on community resources to enhance health status. ${ }^{2-5}$ In response to IPV, a collaborative coordinated

Barbara J. Maciak is a health scientist, Urban Research Centers, Centers for Disease Control and Prevention, assigned to the Detroit Community-Academic Urban Research Center, School of Public Health, University of Michigan. Ricardo Guzman is the executive director of Community Health and Social Services Center (CHASS), Detroit, Michigan. Anna Santiago is an associate professor and the director of the Office of Research, School of Social Work, Wayne State University, Detroit, Michigan. Graciela Villalobos is the program director of Child and Family Services, Southwest Detroit Counseling and Development Center (fomerly Southwest Detroit Community Mental Health Services). Barbara A. Israel is a professor, chair of the Department of Health Behavior and Health Education, and principal investigator for the Detroit Community-Academic Urban Research Center, School of Public Health, University of Michigan.

Address reprint requests to Barbara J. Maciak, PhD, University of Michigan School of Public Health, Department of Health Behavior and Health Education, 1420 Washington Heights, Ann Arbor, MI 48109-2029; e-mail: bjmaciak@umich.edu.

Health Education \& Behavior, Vol. 26 (6): 821-840 (December 1999)

(C) 1999 by SOPHE 
community response (CCR) model has evolved across the United States that includes a range of partners representing various agencies and systems (i.e., social service, medical, criminal justice, education, clergy, government, business, and media), as well as community members and survivors of IPV themselves. ${ }^{6}$ In this model, each partner plays a role that may include identifying and treating abuse through routine screening, providing legal protection and advocacy for abused women, supporting batterer intervention programs, or providing conflict resolution and communication skills training. Social change models are concerned with increasing community problem-solving ability to redress power imbalances between oppressed or disadvantaged groups and the larger society. These models emphasize the need for a comprehensive approach to violence prevention that integrates community support systems and addresses women's needs for housing, child care, economic stability, physical and emotional safety, career development and job training, education with regard to family violence, and ongoing support groups and peer counseling. ${ }^{7-9}$

The methods and procedures required to form and sustain community coalitions for health promotion and disease prevention (e.g., cardiovascular disease, cancer, alcohol, tobacco, substance abuse, and HIV/AIDS) have been widely described. ${ }^{2,10-14}$ However, there is little published literature examining the development of community coalitions or partnerships working to address the problem of IPV, particularly in ethnic minority communities. Health promotion coalitions described in the literature rarely include representation from ethnic minority communities. ${ }^{15} \mathrm{CCR}$ systems to address IPV are frequently citywide or countywide, with leadership based in criminal justice or local domestic violence agencies, often with limited involvement and influence of ethnic minority community-based organizations (CBOs). While the needs of ethnic minority subcommunities may be considered, preventive and support services are often culturally inappropriate for ethnic minority women and men in these communities.

This article addresses the need for a greater understanding of the formative stages of locally based and controlled partnerships addressing IPV within ethnic minority communities of identity. Specifically, the article describes and analyzes the evolution of the LA VIDA partnership within a community-based participatory research framework using a case study approach that draws on information available from the early stages of context and process evaluation. The challenges and lessons learned in addressing a complex, multifaceted problem such as IPV in an ethnic minority community are highlighted through an examination of the process of mobilizing diverse partners, conducting community diagnosis and needs assessment activities, establishing goals and objectives

The authors acknowledge the dedication and contribution of LA VIDA partners, including the Community Health and Social Services Center (CHASS), Southwest Detroit Counseling and Development Center, Latino Family Services (LFS), the Community Outreach Program and Cabrini Clinic of Most Holy Trinity Church, the Detroit Hispanic Development Corporation, Vistas Nuevas Head Start, SER-Metro Detroit, the University of Michigan School of Public Health (UM-SPH), First Step, Interim House, My Sister's Place/ Women's Justice Center, the Detroit Police Department, the Wayne County Prosecutor's Office, and the Wayne County Coordinating Council to Prevent Domestic Violence. In addition, we acknowledge partners of the Detroit Community-Academic Urban Research Center (Detroit URC), including the Butzel Family Center, CHASS, Friends of Parkside, the Kettering/Butzel Health Initiative, LFS, the Warren/Conner Development Coalition, the Henry Ford Health System, the Detroit Health Department, UM-SPH, and the Centers for Disease Control and Prevention (CDC); the Urban Research Centers, Division of Prevention Research and Analytic Methods, Epidemiology Program Office, CDC; and the Family and Intimate Partner Violence Prevention Team, Division of Violence Prevention, National Center for Injury Prevention and Control, CDC. The LA VIDA Partnership received initial seed funding from the CDC through the Detroit URC. 
within a social ecological framework, and integrating evaluation during the development phase. Implications for health educators working in partnership with ethnic minority communities to address the problem of IPV are suggested.

\section{PROBLEM STATEMENT}

\section{Intimate Partner Violence Against U.S. Latina Women}

There is relatively little information about IPV against the growing population of Latina women in the United States. The only national study of violence in Hispanic families in the United States found Latina women to be at higher risk than non-Latino Whites for physical violence in marriage.$^{16}$ Major factors that may contribute to higher levels of abuse among Latina women, and encourage many battered Latina women to forgo formal support services, include cultural characteristics such as machismo (male privilege and dominance), marianismo (female submission and passivity), and simpatico (emphasizing smooth and pleasant social relationships); extended family structures with rigidly defined sex roles; and a strong Catholic tradition, particularly among Mexican women. ${ }^{17-22}$ These cultural tendencies are not generalizable but rather vary with education, level of acculturation, immigration status, income, and country of origin. ${ }^{23}$

While IPV crosses all ethnic and class lines, there is a severe lack of culturally competent services and responses designed to address the needs of battered women from ethnic minority communities. ${ }^{24-27}$ Programs addressing IPV among Latinos include La Clinica de la Raza (implementing Proyecto Cambio [Project Change] and a traditional rites of passage ceremony that includes education about IPV for young girls), the Latino Families at Risk program (helping low-income Latino families address IPV through education and support groups, self-esteem building for women, and batterer counseling), De Madres a Madres (addressing IPV as a major barrier to prenatal care), and the Lideres Campesinas/ Immigrant Outreach Services program (enhancing IPV knowledge, awareness, and support among Latina women in rural migrant farmworker communities). ${ }^{28-31}$ These programs evolved from the input of local community members and address local needs and have local relevance. While formal services and shelters provide an option for some women, alternative services are needed for the majority of Latina women who may seek support but will not leave their homes or communities for cultural or financial reasons or, among recent immigrants, for fear of deportation. For these women, community-based outreach programs, support groups, and counseling opportunities designed in partnership with local community members may be most appropriate.

\section{Cultural and Historical Context of Southwest Detroit}

The LA VIDA partnership is centered in southwest Detroit, a multiethnic urban area of Detroit with approximately 78,000 residents, including nearly 20,000 Latinos (23\%, which is nearly two-thirds of all Latinos residing in Detroit); African Americans (30\%); non-Hispanic Whites (33\%); and persons of Arabic, Indian, or other ancestry (14\%). ${ }^{32}$ The majority of southwest Detroit Latinos are of Mexican (60\%) or Puerto Rican (30\%) ancestry, with Cubans and other Central and South Americans constituting the remaining $10 \%$ of the population. Approximately $40 \%$ of the southwest Detroit Latino population comprises undocumented migrants and legal permanent residents without citizenship 
status. ${ }^{32}$ Historically, southwest Detroit Latinos of differing ethnicity have lived and worked together amicably.

Since the early 1900s, southwest Detroit has served as a core area for Latino migration and settlement, with Mexican and Puerto Rican workers migrating to join the ranks of unskilled and semiskilled laborers employed at nearby automobile plants. ${ }^{33,34}$ Like most inner-city neighborhoods of Detroit, the vibrant and growing southwest Detroit community was devastated by the economic recession of the 1970s and 1980s. Civil disturbances during the 1960s contributed to widespread neighborhood disinvestment and outmigration of residents to suburban areas. Since 1990, a renewed interest in economic development has been sparked by a resurgence of Latino migration and the designation of southwest Detroit as part of a federally funded empowerment zone. ${ }^{35}$ Nonetheless, there remain a significant number of low-income families with young children in southwest Detroit (61\% of the population lives below the poverty line), the unemployment rate was more than $30 \%$ in 1990, and a sizable immigrant population engaged mainly in seasonal construction work contributes to an estimated medically uninsured rate of $59 \% .^{32,36}$ The higher incidence of IPV reported among Latino families with a low-income and unemployed male head of household suggests a link between economic stress and IPV, and underscores the importance of considering the local economic situation when addressing the problem. ${ }^{16}$

The Latino population of southwest Detroit shares a common geographic locale with residents of diverse cultures and ethnicities. As such, the Latino "community" may be characterized as a unit of identity (not a geographic catchment area) joined by natural support systems (i.e., extended family and friendship groups, local informal caregivers, religious institutions, and social clubs), common symbol systems (i.e., similar language, rituals, and ceremonies), shared values and norms, shared needs and commitment to meeting them, and a shared emotional connection through common history and experiences. ${ }^{37,38}$ Within the southwest Detroit Latino community, different ethnic subgroups (e.g., Mexican, Puerto Rican) may self-identify as separate units of identity or subcommunities. As will be discussed below, the recognition of the community as a unit of identity rather than as an aggregate of individuals living in a geographic area has important implications for the establishment of coalitions and partnerships addressing concerns such as IPV.

Since the early 1990s, concern about crime and violence has grown among southwest Detroit Latinos. In a 1991-1992 survey, $40 \%$ of 176 Latina women aged 18-65 in southwest Detroit reported experiencing at least one incident of physical abuse during the year prior to the survey, $70 \%$ experienced incidents of emotional abuse, and more than $50 \%$ experienced both physical and emotional abuse. ${ }^{39}$ Immigrant women were significantly less likely to report either physical or psychological abuse than Detroit-born women of Mexican origin. ${ }^{40}$ Fewer than half of those women experiencing abuse told their families, and only 1 of 10 reported that they would use formal services. Of those who sought help, one-third contacted a clergy member for support. ${ }^{39}$ Underutilization of formal services was highest among older, monolingual Spanish-speaking women and those with minor children in the home because of a lack of knowledge and/or access to culturally competent services and inadequate financial resources to leave the abusive relationship. ${ }^{41}$

Although southwest Detroit police precinct personnel describe a large volume of calls from Latina women reporting physical abuse, fear of arrest and/or deportation (i.e., of victims, their families, and abusers) among some undocumented Latino residents results in the majority of these cases not being prosecuted in court. This suggests that many IPV cases occur among undocumented residents, and adds to the uniqueness of working to 
address IPV within the Latino community compared with other ethnic communities of identity (e.g., African American). While recent reforms in U.S. immigration and welfare law have incorporated provisions to protect the rights of immigrant victims to seek legal recourse and receive services, there still exists among southwest Detroit Latinos considerable misinformation about these provisions and mistrust of government agencies, including Immigration and Naturalization Services (INS). Moreover, petitioning INS for early consideration of residency, citizenship, or asylum on the basis of IPV is quite complicated, and petitioners are frequently unsuccessful in meeting the burden of proof required by INS to receive permission to remain in the United States. ${ }^{42}$

In 1996, 102 of 146 Latino community members (69\%) interviewed as part of an informal community assessment cited violence, including family and IPV, as a serious problem. ${ }^{43}$ During the mid-1990s, attempts by southwest Detroit CBOs to address the problem of IPV were hampered by changes in organizational leadership, the sensitive nature of the issue, lack of widespread involvement among diverse partners, and insufficient resources.

\section{UNDERLYING PRINCIPLES}

\section{Community-Based Participatory Research: A Partnership Approach}

Community-based participatory research (CBPR) in public health is a collaborative approach to research that equitably involves community members, organizational representatives, and researchers in all aspects of the research process. ${ }^{44}$ Key principles of CBPR include recognizing community as a unit of identity, building on community strengths and resources, facilitating collaborative partnerships, integrating knowledge and action for mutual benefit of all partners, promoting an empowering process that attends to social inequalities, addressing health from an ecological perspective, and disseminating findings and knowledge gained to all partners. ${ }^{44,45}$ In keeping with these principles, the LA VIDA partnership developed out of the Detroit Community-Academic Urban Research Center (Detroit URC), one of three urban centers for applied research in public health established in 1995 with support from the Centers for Disease Control and Prevention (CDC). The Detroit URC is committed to a CBPR approach aimed at strengthening the ability of communities in southwest Detroit and on the east side of Detroit to address health concerns. ${ }^{46-48}$ The affiliation of two key southwest Detroit CBOs with the Detroit URC facilitated the establishment of the LA VIDA partnership (see the Establishing LA VIDA section for a description of the process and partners involved). The extent to which and how the LA VIDA partnership has incorporated CBPR principles into its actions during its development phase will be examined in this article.

\section{METHOD}

The case study presented here draws on multiple sources of data, including individual interviews with LA VIDA partners, a structured group discussion and feedback session with LA VIDA partners, minutes from monthly LA VIDA partnership meetings, and field notes collected over a 2-year period. Individual interviews with 15 LA VIDA partners (representing CBOs, health and social service agencies, police and the criminal justice system, and domestic violence agencies) were conducted by the URC academic 
researcher and a community organizer located at the Community Health and Social Services Center (CHASS). These interviews included questions about ongoing programs and services, concerns about IPV against Latina women, experiences dealing with IPV in the community, and expectations with regard to a community partnership to address IPV. The structured group interview, conducted by a member of the partnership from academia, was administered to representatives from CBOs and agencies involved in the LA VIDA partnership since early 1998 and included both descriptive and reflective questions (e.g., In what ways, if any, is the LA VIDA partnership unique or different from other community coalitions or partnerships in which you may have participated? Why? What have been the significant barriers or challenges facing the LA VIDA partnership? What lessons can be learned from our experience of mobilizing diverse constituents?). Field notes consisted of written descriptions of observations and experiences in the community, direct quotations, and field-generated insights and interpretations. ${ }^{49}$ Content analysis techniques were used to analyze the field notes and data collected from the group discussion and interviews. ${ }^{49}$ Major themes were identified initially by the lead author, and these were shared, discussed, and revised as appropriate with the coauthors who are participants in the partnership.

\section{ESTABLISHING THE LA VIDA PARTNERSHIP: DEVELOPMENT AND PROGRAM PLANNING}

The LA VIDA partnership is affiliated with the Detroit URC, a partnership involving collaboration among six Detroit CBOs (the Butzel Family Center, CHASS, Friends of Parkside, the Kettering/Butzel Health Initiative, Latino Family Services (LFS), and the Warren/Conner Development Coalition), the Henry Ford Health System, the Detroit Health Department, the University of Michigan School of Public Health (UM-SPH), and the CDC. In 1996, Detroit URC board members identified family and IPV as a priority area for developing future CBPR projects. Board members from CHASS and LFS (who represent the southwest Detroit Latino community) expressed the long-standing concerns within southwest Detroit about the widespread problem of IPV against Latina women and the absence of culturally competent preventive and support services. The community-driven effort to address IPV against Latina women became a project of the Detroit URC. CHASS assumed the "lead" agency role in this effort, and a Detroit URC board member, affiliated with the UM-SPH and the CDC, assumed the lead academic researcher role. Over a period of several months during mid-1997, the URC academic researcher met periodically with the director of CHASS to discuss an approach to the IPV initiative. Regular updates have been provided to the Detroit URC board through all stages of the planning process.

\section{The Early Stages: Mobilizing Diverse Partners}

Not all members entered into the LA VIDA partnership at the same time; rather, a process and sequencing occurred over a period of about 1 year. In October 1997, the director of CHASS called a meeting of the directors of several key health and social service agencies serving the southwest Detroit Latino community. Reflecting on the critical factors that hampered earlier attempts to address IPV in southwest Detroit (i.e., unstable leadership, the sensitive nature of the issue, and lack of widespread involvement among diverse partners), the lead agency director sought assurances of support from the other 
agency directors. The director of CHASS was aware that culturally competent agencylevel services needed to be available within the community before open dialogue with Latina women could begin. The meeting was held at a local restaurant, on neutral ground, to emphasize joint ownership of the problem and shared responsibility for working toward its solution. The agenda included discussion about the growing visibility of IPV within the community, the need to better understand the specific concerns of Latina women (thus, the need for a targeted neighborhood "assessment"), the desire to proceed slowly and cautiously because of the sensitive nature of the issue, and the need to establish a broad base of community support with diverse partners.

From this initial gathering, a request was made to participating agency directors to appoint a staff representative who would serve on a community advisory group (CAG) to work with the URC academic researcher to identify concerns that would need to be addressed to ensure the success of this effort. A part-time community organizer (already on staff at CHASS) was identified to assist the academic researcher by facilitating community connections. During November 1997, the URC academic researcher and community organizer conducted interviews with agency staff identified to serve on the advisory group to learn about ongoing programs and services, discuss the proposed initiative, and explain the function of the proposed CAG. These early interactions with agency directors and staff provided a foundation for ongoing community diagnosis activities and for relationship building and partnership formation. CAG members included representatives from CHASS (a comprehensive community health center), Southwest Detroit Counseling and Development Center (a comprehensive community mental health agency), LFS (a social service agency), SER-METRO Detroit (a technical training institute), the Detroit Hispanic Development Corporation (a grassroots agency promoting youth development and job training), the Community Outreach Program and Cabrini Clinic of Most Holy Trinity Catholic Church, Vistas Nuevas Head Start, and UM-SPH.

With the exception of CHASS (the lead agency representative), all CAG members were initially female. This may reflect the perception of IPV within the southwest Detroit Latino community as a "women's" issue and/or a desire for empowerment or ownership of the problem among Latina women. The importance of male involvement in the IPV initiative was discussed periodically during this early formative stage of the LA VIDA partnership, although members expressed their view that a female-dominated CAG did not reflect a lack of concern or interest among males, and that additional male representatives would be invited to participate over time.

From January to June 1998, the CAG met regularly to discuss concerns related to IPV in southwest Detroit. The members shared information (e.g., reports, journal articles) about IPV in general and in Latino communities specifically, and considered strategies for moving forward. Through these discussions, members recognized the importance of collaboration with additional partners from law enforcement, criminal justice, and local domestic violence agency/shelter programs. In response, the URC academic partner and the community organizer held individual meetings with representatives from these various agencies and institutions to inform them of the IPV initiative within southwest Detroit and to begin building relations. Although each group contacted in this process indicated a strong interest and willingness to work with the Latino community, collaboration between these additional groups and the LA VIDA partnership did not happen immediately. Rather, each was invited to meet with the CAG (i.e., the initial core group of LA VIDA partners) to describe their ongoing programs and services and discuss IPV issues and concerns. 
In May 1998, a panel presentation was held with CAG members and southwest Detroit police precinct officials, county prosecutor's office representatives, and an INS attorney to further discuss IPV policy and legislation and the unique challenges of addressing IPV against Latina women. This was seen as particularly important given the historic mistrust of law enforcement and government agencies by the Latino community, as discussed earlier. Although relationships between southwest Detroit police precincts and community members have improved in recent years (as staffing patterns evolved to include a greater percentage of Latino officers), the need for culturally competent police training on IPV was identified as a strategy for further increasing police sensitivity to Latina women's concerns. In June 1998, CAG members held a separate meeting with representatives from three county domestic violence agencies to further discuss the needs of abused Latina women and consider strategies for developing culturally competent services.

Throughout 1998, CAG members considered ways in which all partners, including those within and outside the Latino community, could work together to address IPV against Latina women. Maintaining ownership and control of the IPV initiative within the Latino community became a critical concern that was eventually discussed openly with diverse organizations. By mid-1999, representatives from law enforcement, criminal justice, and domestic violence agencies were invited to join LA VIDA as collaborating partners. LA VIDA community partners (i.e., representatives from CBOs within the Latino community) are currently engaged in similar dialogue with church officials, educational institutions, local businesses and corporations, and other groups outside the Latino community to lay the groundwork for effective collaboration based on mutual understanding and trust.

\section{Management, Staffing, and Group Process}

As a respected leader in southwest Detroit, the director of CHASS assumed a primary leadership role in establishing the LA VIDA partnership by facilitating community connections, sharing his perspectives on community politics, and providing oversight for project activities. The URC academic partner conducted background research, developed research protocols, and assumed primary responsibility for grant proposal writing. The community organizer assisted with various administrative tasks and acted as community liaison. Seed money provided by the CDC through the Detroit URC was used to hire the part-time community organizer and support monthly meetings.

From January 1998 to the present, CAG meetings (eventually referred to as LA VIDA partnership meetings) have been held on a monthly basis. These meetings were initially held at CHASS, and later on a rotational basis at other member agencies to ensure a sense of joint ownership. Prior to each meeting, a draft agenda prepared by the URC academic partner and CHASS director was sent to members for their input. Meetings were generally opened by the CHASS director and facilitated by the URC academic partner; whenever feasible, a UM-SPH graduate student took field notes.

In late 1998, as trust among partners grew and long-term commitment to the initiative was apparent, partners began reflecting on a common purpose and operating principles. LA VIDA partners agreed to uphold a set of operating principles as follows: (1) mutual respect and equal participation among all partners, (2) recognition that all partners have knowledge and expertise to share, and (3) recognition that community-based efforts to prevent IPV require a collaborative process that is mutually beneficial to all partners involved. In practice, these principles have been implemented over time through a continuous process involving shared experiences that served to reinforce the commitment 
and roles of various partners in addressing IPV. Partners considered approaches to group decision making and, eventually, chose consensus as a decision-making strategy.

\section{Establishing an Identity: Mission and Goals Statement}

As described above, during the early stages of this initiative, prior to developing a sense of common purpose, the core group of partners was considered a community advisory group. By mid-1998, after the group had met for a period of 6 months, members began to reflect on their mission and goals. Members decided that they were more than an advisory group and sought an identity that reflected the purpose for which they convened. By June 1998, the group became known as the Southwest Detroit Task Force to Prevent Domestic Violence Against Latina Women. By January 1999, as trust grew and relationships developed further, the group reconsidered its identity as a task force and decided that the term partnership reflected more adequately both the long-term commitment of members to addressing the IPV problem and the principles of mutual respect and equal participation followed in a CBPR approach. Equipped with increased knowledge about IPV itself, members further refined the focus of the initiative from domestic violence to intimate partner violence to reflect more precisely the emphasis on abuse against a woman by a male spouse or partner. Most important, members felt very strongly about the need for the initiative to be readily identifiable in the Latino community, as well as in the larger community of service providers. Thus, the name LA VIDA (Latinos Contra la Violencia intíma en el Suroeste de Detroit)—-the Southwest Detroit Partnership to Prevent Intimate Violence Against Latina Women - was finally agreed upon.

Concurrent with establishing trusting relationships and seeking identity, LA VIDA members developed, through an iterative process, an overall direction for the partnership in the form of a mission and goals statement. This mission statement is as follows: "LA VIDA—-the Southwest Detroit Partnership to Prevent Intimate Violence Against Latina Women - seeks to ensure the availability, accessibility, and utilization of a range of culturally competent IPV prevention and support services for Latino women and men in southwest Detroit." The goals of LA VIDA are (1) to establish a partnership facilitating collaboration among CBOs, health and social service agencies, police and the criminal justice system, religious institutions, academe, and other groups committed to preventing IPV against Latina women; (2) to collect, analyze, and disseminate information about IPV against Latina women (e.g., causes, consequences, barriers to service delivery, and strategies for improving services) for program planning and educational purposes; and (3) to develop, implement, and evaluate locally relevant, culturally competent prevention and intervention activities aimed at reducing IPV against Latina women in a way that builds upon the local knowledge of community members and contributes to community empowerment and capacity building.

\section{Community Diagnosis and Needs Assessment Activities}

Information gathered through assessment activities provides a basis for planning, stimulating change or action, and empowerment ${ }^{50}$ While conducting a traditional assessment of resources and needs is a necessary component of program planning, the information is not sufficient for designing sustainable solutions. ${ }^{51}$ A community diagnosis process carried out continuously throughout the program is much broader than a needs 
assessment and aims to understand many facets of a community including culture, values and norms, leadership and power structure, means of communication, helping patterns, important community strengths and institutions, and history. ${ }^{52}$ This information is critical for understanding which interventions are likely to be effective and who needs to be involved in the process. For the URC academic researcher member of the LA VIDA partnership, the early interactions with agency staff and community members (along with several "windshield tours" of southwest Detroit with the community organizer) provided a framework for an ongoing community diagnosis that helped the academic partner to develop a deeper understanding of the community and its culture. Information from the community diagnosis has assisted LA VIDA partners to identify community assets, additional collaborating partners, and potential implementation barriers, and to begin assessing training needs within the community. For example, discussions with local clergy revealed the existence of a church-affiliated "moms and tots group" that meets weekly and may provide a forum for involving Latina women in the discussion of issues related to IPV. Likewise, early interactions with domestic violence agency personnel revealed the need for cultural competency training among non-Latino counselors and support staff.

In addition to the community diagnosis, LA VIDA partners have worked collaboratively to develop plans for a more formal needs assessment aimed at understanding the causes and consequences of IPV in the community, risk and protective factors, and helpseeking strategies and barriers to help seeking, and identifying possible prevention and intervention strategies. For this portion of the assessment, focus group discussions and in-depth interviews will be conducted among various community groups (i.e., Latino men and women, clinical and social service providers, and adolescent girls and boys). LA VIDA partners decided upon the composition of the focus groups (taking into consideration ethnicity, immigrant status, length of time in the United States/Detroit area, and marital status), participant recruitment strategies, question content, 2-day training for focus group facilitators and note takers (including basic information about qualitative research, instructions on the discussion guide, confidentiality, and probing techniques), participant compensation, informed consent procedures, and strategies for disseminating findings within the community. To build capacity and promote empowerment, community members will receive training to serve as cofacilitators for focus group discussions. Involving LA VIDA partners in all aspects of the needs assessment planning process has helped to ensure a culturally acceptable and scientifically sound research approach and a groundwork for broad community involvement in follow-up prevention and intervention activities.

\section{Program Planning Within an Ecological Framework}

Programs to address IPV are shifting away from single-risk-factor approaches in favor of models that examine the interactions of factors across individual, social, and cultural domains. ${ }^{53}$ From an ecological perspective, health behavior and health status are viewed as affecting, and being affected by, multiple levels of influence including intrapersonal (or individual), interpersonal, organizational, community, and public policy. ${ }^{54}$ Within each level, the targets of change and possible prevention and intervention strategies are extensive. This ecological framework provides a useful guide for moving beyond categorical approaches to addressing the complex multifaceted problem of IPV. For example, widespread unemployment and shortages in affordable housing (community- and public policy-level issues) may undermine both violence prevention and women's ability to maintain independent living situations after shelter stays. Consideration must be given to 
women's needs for housing, child care, economic stability, physical and emotional safety, and career development and job training, as well as to education and counseling with regard to family violence.

LA VIDA partners used an ecological model as a framework for identifying IPV prevention and intervention activities (targeting Latino men and women, including adolescent girls and boys, service providers, and other groups) that need to be accomplished over a 5-year period and beyond. A 5-year time frame was chosen by partners to ensure adequate time for implementing a range of IPV prevention and intervention activities, and to coincide with standard funding cycles of potential donor agencies and foundations. Partners agreed that assessment findings would be used to guide the further development of interventions. Specific program objectives were developed as follows: (1) to increase coordination and collaboration among community partners; (2) to describe existing IPV prevention resources, risk/protective factors for IPV, help-seeking practices, and perceived barriers to help-seeking among Latino men and women; (3) to increase the knowledge of community members, service providers, policy makers, and researchers/professionals about IPV; (4) to increase the knowledge, skills, and competence (including cultural competence) of clinical/social service providers and other community members to identify Latina women experiencing or at risk for IPV, and to provide appropriate treatment, referral, and/or follow-up; (5) to increase the number of Latina women (including adolescent girls) referred to and/or using IPV prevention and intervention services (e.g., medical, legal, and/or social support services); (6) to increase social support for Latina women experiencing or at risk for IPV; (7) to increase prevention and intervention services for Latino men (including adolescent boys) involved in or at risk for battering; (8) to increase knowledge and change attitudes/norms among adolescent girls and boys with regard to IPV and healthy relationships; and (9) to increase support for Latino children who witness IPV. These objectives and related activities form the basis for the development of grant proposals to obtain funding for program implementation.

\section{Integrating Evaluation Within the Development Process}

As the LA VIDA partnership evolved and assessment and intervention activities were considered, planning for evaluation began. Two components of the evaluation plan, one addressing the partnership itself and another the specific interventions, were considered. Partners agreed on a participatory, formative approach to the evaluation of the LA VIDA partnership in order to ensure local relevance and increase the usefulness of the results, and use routinely available evaluation findings to guide and shape the partnership over time. The progress of the LA VIDA partnership toward meeting its goals will continue to be assessed through an examination of major partnership activities, the process by which the partnership has developed, factors that affect both positively and negatively the intended goals of the partnership (i.e., barriers and facilitating factors), and the experience and satisfaction of LA VIDA partners. A detailed protocol for this component of the evaluation is being developed jointly by LA VIDA partners to guide the conduct of three types of evaluation. First, a context evaluation will be carried out to consider how events, influences, and changes that occur naturally in the environment may contribute to or impede success of the partnership. Second, a process evaluation will continue to be conducted to determine the extent and quality of implementation (e.g., examining start-up processes, quality and completeness of activities, strengths and weaknesses of the program, and partner satisfaction). Third, an impact evaluation will document the degree to 
which LA VIDA activities have had an effect on knowledge, attitudes, behaviors, infrastructures, and/or social environments that are related to specific longer term health outcomes. ${ }^{54,55}$ Process and context evaluation findings available to date (and described below) have been shared with partnership members for reflection and for making agreed-upon changes. Separate evaluation plans, linking outcomes with objectives, will be developed for specific interventions supported by the partnership.

\section{SUMMARY OF MAJOR ACCOMPLISHMENTS TO DATE}

Over the past 2 years, LA VIDA partners have succeeded in mobilizing diverse partners, establishing trust among partners involved, developing a mission and goals statement, adopting operating principles that build on the CBPR principles of the Detroit URC, outlining a 5-year activity plan with broad program objectives that consider the social ecology of IPV, developing a grant proposal, and obtaining seed funding from the $\mathrm{CDC}$ for program start-up and assessment activities. The following sections present the results of the analysis of context and process evaluation data described earlier. Selected quotations are included to share the opinions of participants.

\section{CHALLENGES}

While the LA VIDA partnership has achieved progress during its early, formative stage, there have been challenges, tensions, and barriers related to the development of the partnership and the relationships between partners. Major challenges identified by LA VIDA partners are described below; although interrelated, they are disentangled and presented as separate issues. Based on these challenges, lessons learned and suggestions for creating partnerships to address IPV in ethnic minority communities will be provided.

1. Maintaining Ownership Within the Latino Community. To ensure that the initiative remained community owned, agencies with Latino leadership and/or experience in working with Latina women were approached first. A key challenge in the process of partnership building has been to remain grounded in the issues and concerns raised from within the local community of identity yet enlist and sustain interest in IPV issues among diverse collaborating partners who come from outside the community. In the words of one Latino community partner, "This is our problem, and we're the only ones who can take it on. Others just can't understand in the same way. It's not just a matter of translation. It's more than that. We need them [other agencies outside the Latino community], and so we have to help them understand. We know that now." Challenges and conflicts in CBPR also arise in relation to how the community is defined and the extent to which partners from CBOs represent community members. ${ }^{44}$ In this initiative, LA VIDA partners from southwest Detroit CBOs self-identify as community residents, representing agencies that developed out of local grassroots initiatives.

2. Lack of Trust and Respect. Low-income Latino communities exhibit a lack of trust of the "outsider's" intentions based on historical experiences with "hit and run" projects and a perceived lack of equal power and respect in program and research development. ${ }^{56,57}$ Trust building is a process that takes place over time, and, once established, trust cannot be taken for granted; researchers must continually prove their trustworthiness. ${ }^{44,58,59}$ After nearly 2 years, a LA VIDA community partner shared what her initial 
reaction had been to the URC academic partner: "In the beginning, it was like, who is this person coming to do research? Research, research, again." Lack of trust among community partners, resulting from competition for scarce resources, turf issues, and/or differences in opinion about the "most" important problems and solutions, can prove challenging as well. "Until now, we [different CBOs involved] all had our own agenda. This time, we leave our [personal/ agency] agenda at the door when we walk in."

3. Striking a Balance Between Research and Action. For frontline service providers, CBPR may be perceived as taking time and resources away from the provision of services, or as part of an academic agenda. Creating a balance between research and action that is mutually agreed upon by the partners involved is an ongoing challenge. ${ }^{44,61}$ One LA VIDA community partner conditioned her support for assessment-related research on the assurance that the data were not "being collected for someone's PhD dissertation." Given the lack of culturally competent IPV services in the community, LA VIDA partners had to strike a balance between "doing something now" and designing a strategic plan to assess needs that would provide a basis for developing and implementing services. During the earliest stages of this initiative, LA VIDA partners argued that "we can't afford to wait any longer ... it's a matter of ethics," and "I see women coming in [facing this issue] every day. ... We've waited way too long already. Something has to be done now." While LA VIDA partners have come to agree on the need to collect additional data to inform interventions and tailor culturally competent services, they also recognized the need to explore short-term mechanisms to serve battered women and their families. Among these mechanisms are better information sharing, referral, and networking among and between partners and existing community resources. In addition, tensions between community and academic partners with regard to evaluation research may reflect misunderstandings about the purpose of the evaluation. Over time and with discussion, LA VIDA partners came to realize that well-documented and soundly evaluated successes will help ensure fiscal viability and even attract additional financial resources to support promising programs. Funds awarded to LA VIDA by the CDC's Division of Violence Prevention helped to reinforce the value of scientifically sound, culturally competent evaluation protocols.

4. Lack of Knowledge About Cultural Differences With Regard to IPV. Lack of exposure and familiarity with the social and cultural context of low-income Latino communities can create barriers between some outsiders (e.g., citywide agencies, academic researchers) and community members. ${ }^{48,56-60}$ Misunderstandings may be most dramatic when the outsider speaks a different language (and professional jargon) and has a different cultural perspective than the community members, for example, in relation to issues of politeness, social interactions, asking questions, and respect for their time ${ }^{56}$ Cultural competency and respect for the local community are critical for lowering sociocultural barriers, and strong organizational and interpersonal skills are essential to facilitate the complex collaborative process. One partner noted that "having prior [IPV] experience and language ability [on the part of the researcher/facilitator] is less of an issue when [he or she] acknowledges and uses the knowledge base within the community." Pairing researchers with community organizers and supporting ongoing community diagnosis activities can help to address this issue. ${ }^{25,51,52,62}$

5. Lack of Funding for Development Activities. Funders often do not provide financial support for these early stages of the development process, making it difficult to establish the foundation necessary to sustain partnerships and systematically plan collaborative initiatives. ${ }^{63}$ This is particularly critical in ethnic minority communities where existing service providers are already overextended with the daily challenges of serving clients on limited resources. Noted one partner, "In the past, we didn't have a facilitator and com- 
munity organizer to help move this process along. We [current LA VIDA partners] always cared, but we all have full-time jobs and weren't able to do what was needed." Long-term sustainability of IPV partnerships requires secure funding for IPV services provided by all partners. The necessity and practicality of a "lead" agency/subsidiary agency structure must be mitigated with the need to financially support IPV services offered by these subsidiary agencies. Within the LA VIDA partnership, CHASS has worked to ensure that all partners receive the financial and technical support required to implement agreed-upon IPV prevention and support activities. A concomitant challenge, then, is to clearly identify the service roles that will be provided by the relevant partners and to develop appropriate mechanisms for coordination.

\section{FACILITATING FACTORS AND LESSONS LEARNED: IMPLICATIONS FOR HEALTH EDUCATION}

Various facilitating factors and strategies have been used in CBPR to address the challenges described above. In this section, facilitating factors and lessons learned from this case study are presented as recommendations for health educators involved in establishing and maintaining effective community-based partnerships aimed at addressing IPV within ethnic minority communities. Health educators can play a key role as facilitators of such partnerships working to address the challenges and lessons learned that are described in this article.

1. Maintaining Ownership and Control Within the Local Community of Identity is Essential for Addressing IPV in Ethnic Minority Communities. Community-based approaches to research attempt to identify and work with existing communities of identity. ${ }^{48,64}$ To ensure locally relevant, culturally competent approaches for addressing IPV in ethnic minority communities, initial grounding of the issue (and control of the process) needs to occur in the smallest unit of community identity. Indeed, units of identity are also "units of solution," providing members with support, self-help, and shared values. ${ }^{65}$ This is in contrast to CCR models that begin with a citywide or countywide perspective that may not represent, speak to the unique needs of, or initially be trusted by ethnic minority communities of identity. Although ethnicity (i.e., country of origin) is not a divisive factor among southwest Detroit Latinos, possible tensions between Latino subgroups associated with, for example, economic or citizenship status may need to be considered when addressing IPV in some U.S. Latino communities of identity.

Given the complexity of the IPV problem, there is, then, a need to engage resources and enlist participation from partners beyond the community of identity or solution. Only the local community of identity itself can decide how and when to bring additional partners to the table. ${ }^{65}$ While Latino community leaders recognized the importance of collaboration with a range of diverse partners both within and outside the Latino community, maintaining local ownership was a critical element that influenced the process (i.e., the timing and sequencing) by which partners were mobilized. There is a critical need to establish trust that involves, for example, partners' willingness to listen to one another and agree to disagree, support of local ownership and control, follow-through on agreed-upon decisions, and genuine caring for the participants involved. ${ }^{44}$

2. Strong and Stable Leadership Within Ethnic Minority Communities of Identity is Critical. Strong, stable leadership within the community of identity is critical in the implementation and maintenance of partnership activities. ${ }^{2,10,44}$ Early attempts to mobilize partners to address IPV in the southwest Detroit Latino community were hampered 
by a lack of committed leadership. The leadership and commitment of CHASS during the formative stages of the LA VIDA partnership helped to overcome previous difficulties. Qualities of successful leadership highlighted by LA VIDA partners include a high degree of respect and trust within the community; attention to partner concerns; strong negotiation, problem solving, and conflict resolution skills; ability to obtain resources; a high degree of political knowledge; ability to foster collaboration among members; and access to the decision-making centers of the community. One partner noted, "If not for CHASS, and the level of trust and respect that [the director of CHASS] has in the community, this [developing the LA VIDA partnership] couldn't have been done." Another partner noted: "It's not just CHASS the organization, it's the individual and his respect within the community." By identifying and working closely with such local community leaders, health educators/academic partners can effectively apply their unique research skills and program-planning expertise to addressing the complex problem of IPV.

3. Partners Within the Community of Identity Must Demonstrate a Long-Term Commitment and Readiness to Address IPV. The commitment by LA VIDA community partners has been an important factor in gaining the support and confidence of diverse collaborating partners beyond the community of identity. Formation of the community advisory group in the early stages of the initiative was viewed by diverse partners as an outward symbol of local commitment to address the issue. One partner from outside the community of identity noted, "That's pretty impressive, the fact that a group [from the Latino community] has gotten together and has been meeting for 6 months. ... We'd be happy to join in and do whatever we can." LA VIDA partners agree that sustained commitment and a readiness to change ${ }^{66}$ (and, in the case of IPV, to openly discuss a potentially sensitive topic) are essential for success. In southwest Detroit, the commitment of LA VIDA partners representing key health and social service agencies to address IPV has bolstered the commitment and "readiness" of other community groups to develop culturally competent referral and support services. Given the challenge of lack of funding for development, CBOs and agencies often need to commit personnel time and resources up front to establish the partnership with the understanding that, over time, external funds will be generated to address the issues identified.

4. Community Diagnosis and Assessment Activities Can Help to Understand the "History" and "Cultural Context" of the Community of Identity. A key factor facilitating the successful conduct of CBPR is the ongoing analysis of community strengths, resources, structure, and dynamics. ${ }^{59,67-69}$ The continual process of getting to know the community enhances the relevance of research and has helped LA VIDA partners to identify community assets, collaborating partners, potential implementation barriers, and IPV training needs (including the need for cultural competency training). One partner from outside the community of identity commented: "I see now the needs and concerns of Latinas [in southwest Detroit].... Before, I just thought [existing] screening protocols and training manuals could be, well, maybe translated into Spanish, but used anywhere in the city." Health educators can assist in the assessment process, including documenting and sharing information collected with the partners for incorporation into program planning and research activities. This assistance necessitates recognition of the need to balance research and action, as well as understanding that comprehensive, ecological approaches to address IPV involve long-term, iterative processes including data collection, analysis, reflection, and action. ${ }^{42}$

5. Cultural Competence Must Be Ensured in the Development of CBPR Efforts Addressing IPV in Ethnic Minority Communities of Identity. Issues of culture and ethnicity influence all aspects of the planning process and require careful consideration at each stage to 
inform the development of CBPR efforts. ${ }^{56,57}$ For example, the cultural factors influencing the decision among some Latina women not to report IPV incidents to the police, and to seek help from family members or clergy rather than formal services, must be understood to ensure the development of meaningful, locally relevant interventions. One LA VIDA partner remarked the following in reference to the development of IPV training materials: "It's not just a matter of translation, but of really understanding and making them [IPV training materials and brochure] meaningful for the community." Maintaining ownership and control within the local community of identity will help ensure cultural competency.

\section{LIMITATIONS}

The case study approach used in examining the LA VIDA partnership during its development phase presents some limitations. First, the type and amount of data available for analysis is limited to early stage context and process evaluation data, restricting inferences that can be made about the enduring success of the partnership. Second, the findings presented here in terms of challenges and lessons learned may not be generalizable to all ethnic minority communities of identity working to address IPV. Nonetheless, given the lack of published literature describing the development of community partnerships to address IPV, the uniqueness of the ethnic minority community involved, the serious nature of the ongoing problem of IPV, and the similarity of some of the findings to previous literature, the lessons for health education presented herein contribute to an understanding of this complex issue and strategies for working toward its resolution.

\section{CONCLUDING COMMENTS}

The experience of the LA VIDA partnership during its early stages of development demonstrates the advantages of a CBPR approach in health education to address IPV, especially in ethnic minority communities. Through its emphasis on local ownership and control, the benefits of this approach include ${ }^{42}$ (1) joining partners with diverse skills, knowledge, expertise, and sensitivities to address a complex, multifaceted problem such as IPV; (2) engaging in processes that ensure equal participation and influence, and overcoming distrust of research on the part of communities that have historically been the "subjects" of such research; (3) bridging the cultural gaps that exist between the partners involved; (4) improving the quality and validity of research by engaging local knowledge and local theory based on the experience of the people involved; (5) overcoming the separation of the individual from his or her culture and context that is often evident in more narrowly defined, categorical approaches; (6) aiming to improve the health and wellbeing of the communities involved, both directly by examining and addressing identified needs and indirectly by increasing power and control over the research process; (7) strengthening research and program development capacity among partners; and (8) involving communities that have been marginalized on the basis of, for example, race, ethnicity, class, and gender. ${ }^{42}$ As presented here, the challenges and lessons learned during the development phase of the LA VIDA partnership have implications for health education research and practice related to understanding and addressing IPV in ethnic minority communities of identity. 


\section{References}

1. McLeroy K, Bibeau D, Steckler A, Glanz K: An ecological perspective on health promotion programs. Health Educ Q 15:351-377, 1988.

2. Butterfoss FD, Goodman RM, Wandersman A: Community coalitions for prevention and health promotion. Health Educ Research 8:315-330, 1993.

3. Wandersman A, Goodman RM, Butterfoss FD: Understanding coalitions and how they operate: An "open systems" organizational framework, in Minkler M (ed.): Community Organizing and Community Building for Health. New Brunswick, NJ, Rutgers University Press, 1997, pp. 261-77.

4. Chavis DM: Building community capacity to prevent violence through coalitions and partnerships. J Health Care Poor Underserved 6:234-245, 1995.

5. Andrews AB: Developing community systems for the primary prevention of family violence. Family Comm Health 16(4):1-9, 1994.

6. Shaw B: Planning a coordinated community response, in Family Violence: Building a Coordinated Response. Chicago, American Medical Association, Commonwealth Fund and Maternal and Child Health Bureau, 1996.

7. Wallerstein N: Powerlessness, empowerment, and health: Implications for health promotion programs. Am J Health Promotion 6:197-205, 1992.

8. Loring MT, Smith RW: Health care barriers and interventions for battered women. Public Health Reports 109:328-338, 1994.

9. Friedman LN: Rethinking Social Services for Battered Women. Remarks at the Commonwealth Fund Symposium titled Domestic Violence and Women's Health: Broadening the Conversation, September 20, 1995.

10. Kumpfer KL, Turner C, Hopkins R, Librett J: Leadership and team effectiveness in community coalitions for the prevention of alcohol and other drug abuse. Health Educ Research 8:359-374, 1993.

11. Rogers T, Howard-Pitney B, Feighery EC, Altman DG, Endres JM, Roeseler AG: Characteristics and participant perceptions of tobacco control coalitions in California. Health Educ Research 8:345-357, 1993.

12. Myers AM, Pfeiffle P, Hinsdale K: Building a community-based consortium for AIDS patient services. Public Health Reports 109:555-562, 1994.

13. Clark NM, Baker EA, Chawla A, Maru M: Sustaining collaborative problem solving: Strategies from a study in six Asian countries. Health Educ Research 8:385-402, 1993.

14. Parker EA, Eng E, Laraia B, Ammerman A, Dodds J, Margolis L, Cross A: Coalition building for prevention. J Public Health Management Practice 4(2):25-36, 1998.

15. McLeroy KR, Kegler M, Steckler A, Burdine JM, Wisotzky M: Community coalitions for health promotion: Summary and further reflections. Health Educ Research 8:1-11, 1993.

16. Straus MA, Smith C: Violence in Hispanic families in the United States: Incidence rates and structural interpretations, in Straus MA, Gilles RJ (eds.): Physical Violence in American Families: Risk Factors and Adaptations to Violence in 8,145 Families. New Brunswick, NJ, Transaction, 1990, pp. 341-367.

17. Sorenson SB: Violence against women: Examining ethnic differences and commonalities. Evaluation Review 20:123-145, 1996.

18. Kantor GK, Jasinski JL, Aldarondo E: Sociocultural status and incidence of marital violence in Hispanic families. Violence and Victims 9:207-222, 1994.

19. Neff JA, Holamon B, Schluter TD: Spousal violence among Anglos, Blacks, and Mexican Americans: The role of demographic variables, psychosocial predictors, and alcohol consumption. J Family Violence 10(1):1-21, 1995.

20. Torres S: A comparison of wife abuse between two cultures: Perceptions, attitudes, nature, and extent. Issues Mental Health Nurs 12:113-131, 1991. 
21. Perilla J, Blakeman R, Norris FH: Culture and domestic violence: The ecology of abused Latinas. Violence and Victims 9:325-339, 1994.

22. Gondolf EW: Appreciating diversity among battered women, in Gondolf EW (ed.): Assessing Woman Battering in Mental Health Services. Thousand Oaks, CA, Sage, 1998, pp. 122-123.

23. Sorenson SB, Telles C: Self-reports of spousal violence in a Mexican-American and nonHispanic White population. Violence and Victims 6(1):3-15, 1991.

24. Campbell DW, Masaki B, Torres S: Water on rock: Changing domestic violence perceptions in the African American, Asian American, and Latino communities, in Klein E, Campbell J, Soler E, Ghez M (eds.): Ending Domestic Violence: Changing Public Perceptions/Halting the Epidemic. Thousand Oaks, CA, Sage, 1997, pp. 64-87.

25. Campbell JC, Campbell DW: Cultural competence in the care of abused women. J Nurs Midwifery 41:457-462, 1996.

26. Pinn VW, Chunko MT: The diverse faces of violence: Minority women and domestic abuse. Academic Medicine 72(suppl. 1):S65-S71, 1997.

27. Williams OJ, Becker RL: Domestic partner abuse treatment programs and cultural competence: The results of a national survey. Violence and Victims 9:287-296, 1994.

28. La Clinica de la Raza-Fruitvale Health Project, Inc., National Center for Injury Prevention and Control, Community-Based Primary Prevention Programs to Prevent Intimate Partner Violence for a Safe America [Web site]. Available: http://www.cdc.gov/ncipc/dvp/fivpt/ page11.htm

29. Allen A: Mercy's help Latino families break the cycle of violence in Atlanta. VITA Newsletter of the Institute of the Sisters of Mercy of the Americas, March, 1998, p. 1.

30. McFarlane J, Kelly E, Rodriguez R, Fehir J: De Madres a Madres: Women building community coalitions for health. Health Care Women Int 15:465-476, 1994.

31. Organizacion en California de Lideres Campesinas, Inc.: Farmworker Women's Leadership Network. Fact sheet, Pomona, CA, 1998.

32. Southeast Michigan Census Council, Inc.: 1990 Census Subcommunity Profiles for the City of Detroit. Michigan Metropolitan Information Center, Center for Urban Studies, Wayne State University, United Community Services of Metropolitan Detroit, 1993.

33. Baba ML, Abonyi MH: Mexicans of Detroit. Detroit, MI, Center for Urban Studies, Wayne State University, 1979.

34. Valdes DN: Al Norte: Agricultural Workers in the Great Lakes Region, 1917-1970. Austin, University of Texas Press, 1990.

35. Meredith R: A revival in the motor city. The New York Times, April 11, 1997, late edition, p. D1.

36. Jones JW: Profile of the Southeast Michigan Region's Economy and Labor Market. Detroit, MI, Southeast Michigan Council on Government, 1998.

37. Israel BA, Checkoway B, Schulz A, Zimmerman M: Health education and community empowerment: Conceptualizing and measuring perceptions of individual, organizational, and community control. Health Educ Q 21:149-170, 1994.

38. Delgado M, Humm-Delgado D: Natural support systems: Source of strength in Hispanic communities. Social Work 27(1):83-89, 1982.

39. Santiago AM, Morash M: Strategies for serving Latina battered women. Urban Affairs Annual Review 42:211-227, 1995.

40. Santiago AM: Spouse Abuse Among Mexican Origin Women: An Assessment of "Cultural" vs "Family Stressors" Explanations of Domestic Violence. Paper presented at the annual meeting of the Population Association of America, Washington, DC, March 1997.

41. Viconi-Lopez A: Individual and Institutional Barriers to Help-Seeking Encountered by Battered Women of Mexican Origin. Unpublished bachelor's thesis, Women's Studies Program, University of Michigan, 1997.

42. Ayuda, Inc.: Documentary Requirements for Violence Against Women Act (VAWA) Cases, 1998. Available: http://www.ayuda.org

43. Latino Family Services: A Community Assessment. Detroit, MI, Latino Family Services, 1996. 
44. Israel B, Schulz A, Parker E, Becker A: Review of community-based research: Assessing partnership approaches to improve public health. Ann Rev Public Health 19:173-202, 1998.

45. Schulz AJ, Israel BA, Selig S, Bayer I, Hollis R, Griffin CB: Development and implementation of principles for community-based research in public health, in MacNair RH (ed.): Research Strategies for Community Practice. New York, Haworth Press, 1998, pp. 83-110.

46. University of Michigan: Urban Centers for Applied Research in Public Health: Detroit Community Academic Prevention Research Center [Proposal submitted to the Centers for Disease Control and Prevention in response to Program Announcement 515]. Ann Arbor, University of Michigan, School of Public Health, Department of Health Behavior and Education, 1995.

47. Centers for Disease Control and Prevention: Program Announcement Number 515: Cooperative Agreement for Urban Centers for Applied Research in Public Health. Atlanta, GA, Centers for Disease Control and Prevention, 1994.

48. Detroit Community-Academic Urban Research Center: Community-Based Public Health Research Principles. Ann Arbor, University of Michigan, School of Public Health, July 24, 1996.

49. Patton MQ: Qualitative Evaluation and Research Methods (2nd ed.). Newbury Park, CA, Sage, 1990.

50. Hancock T, Minkler M: Community health assessment or healthy community assessment: Whose community? Whose health? Whose assessment? in Minkler M (ed.): Community Organizing and Community Building for Health. New Brunswick, NJ, Rutgers University Press, 1997, pp. 139-156.

51. Eng E, Blanchard L: Action-oriented community diagnosis: A health education tool. Int $Q$ Comm Health Educ 11(2):93-110, 1990-1991.

52. Steuart GW: Planning and evaluation in health education. Int J Health Educ 2:65-76, 1969.

53. Chalk R, King P: Cross-cutting issues: The ecological context of family violence, in Chalk R, King P (eds.): Violence in Families: Assessing Prevention and Treatment Programs. Washington, DC, National Academy Press, 1998.

54. Israel BA, et al: Evaluation of health education programs: Current assessment and future directions. Health Educ Q 22:364-389, 1995.

55. Francisco VT, Paine AL, Fawcett SB: A methodology for monitoring and evaluating community health coalitions. Health Educ Research 8:403-416, 1993.

56. Zambrana RE: The role of Latino/Hispanic communities in health services research: Strategies for a meaningful partnership. J Medical Systems 20:317-328, 1996.

57. Marin G, Main BV: Enhancing research participation, in Marin G, Main BV (eds.): Research With Hispanic Populations (Applied Social Research Methods Series Vol. 23). Newbury Park, CA, Sage, 1991, pp. 42-60.

58. Courtney R, Ballard E, Fauver S, Gariota M, Holland L: The partnership model: Working with individuals, families, and communities, toward a new vision of health. Public Health Nurs 3:177-186, 1996.

59. Lillie-Blanton M, Hoffman SC: Conducting an assessment of health needs and resources in a racial/ethnic minority community. Health Services Research 30(1):225-236, 1995.

60. Israel BA, Schurman SJ, Hugentobler MK: Conducting action research: Relationships between organization members and researchers. J Appl Behav Science 28:74-101, 1992.

61. Altman DG: Sustaining interventions in community systems: On the relationship between researchers and communities. Health Psychol 14:526-536, 1995.

62. Schulz AJ, Parker EA, Israel BA, Becker AB, Maciak BJ, et al: Conducting a participatory community-based survey: Collecting and interpreting data for a community health intervention on Detroit's eastside. J Public Health Manage Practice 4(2):10-24, 1998.

63. Bogan G, Omar A, Knobloch RS, Leandris CL, O'Rourke TW: Organizing an urban AfricanAmerican community for health promotion: Lessons from Chicago. J Health Educ 23:157$159,1992$. 
64. Israel BA, Checkoway B, Schulz AJ, Zimmerman MA: Health education and community empowerment: Conceptualizing and measuring perceptions of individual, organizational, and community control. Health Educ Q 21:149-170, 1994.

65. Steuart GW: Social and cultural perspectives: Community intervention and mental health. Health Educ Q 20(suppl. 1):S99-S111, 1993.

66. Bowen DJ, Kinne S, Urban N: Analyzing communities for readiness to change. Am J Health Behav 21:289-298, 1997.

67. Eng E, Parker EA: Measuring community competence in the Mississippi Delta: The interface between program evaluation and empowerment. Health Educ Q 21:199-200, 1994.

68. Fawcett SB, Paine-Andrews A, Francisco VT, Schultz JA, Richter KP, et al: Empowering community health initiatives through evaluation, in Fetterman DM, Kafterian SJ, Wandersman A (eds.): Empowerment Evaluation: Knowledge and Tools for Self-Assessment and Accountability. Thousand Oaks, CA, Sage, 1996, pp. 161-187.

69. Mittelmark MB, Hunt MK, Heath GW, Schmid TL: Realistic outcomes: Lessons from community-based research and demonstration programs for the prevention of cardiovascular diseases. J Public Health Policy 14:437-462, 1993. 